\title{
Undervalued and Under-served: the Gifted Disadvantaged
}

\section{Carol van der Westhuizen}

\section{Introduction}

It is a fallacy that the government does not value bright children because it wants to reduce every child to the lowest common denominator. Nothing could be further from the truth (Asmal, 2003:4).

The omission of gifted learners as a special education needs category from policy documents such as White Paper 6 (Department of Education, 2001) in South Africa is cause for concern. Although the White Paper acknowledges that certain learners may require intensive support to develop to their full potential and that learner differences should be respected, "whether due to age, gender, ethnicity, language, class, disability, HIV or other infectious diseases" (Department of Education, 2001:16, 6) it makes no specific mention of gifted learners. Asmal (2003:4) stated that the success of the South African (SA) school system is dependent on providing for the "blossoming of the potential of all our children", but not by isolating gifted learners, since they could "add great value to the potential of other children through collaboration". Naledi Pandor, South Africa's minister of education recently explained: "We must promote the broadest possible view of inclusion, in the sense of social inclusion, which poses challenges for every school that has one or more children who are 'different' in some way. We must embrace and celebrate that difference" (2005:5).

This article reports on an investigation into the provision of gifted education, with special reference to the gifted disadvantaged, and attempts to answer the question as to whether current provision for the disadvantaged gifted is adequate. The driving questions are:

- Does an inclusive system provide adequately for gifted learners?

- What are the causes of the inequity in the representation of different cultural groups in programmes for the gifted?

- How do teachers influence the provision of education for gifted learners?

\section{Context}

The "dismal" state of gifted education in South Africa can be ascribed to the dismantling of the infrastructure created by the previous government, viz. the closing of out-of-school centres which were established for the gifted during the 1980s, the withdrawal from schools 
of specialist gifted teachers and the lack of interest among education authorities (Kokot, 1998:58).

\section{Current provision for the gifted \\ Inclusion}

In South Africa inclusion is a radical concept linked to the transformation of formal institutional arrangements in SA society, among others education, and the governing principles are race, and to a lesser extent, gender. The view of inclusive education as an approach aimed at "rethinking issues of race, class, disability and gender as well as changing structures" (Naicker, 2000:10) and the suggestion that inclusion should reinforce attempts to achieve social justice Carrim (2002:16), are aligned with the Salamanca Statement, the international guideline for developing inclusive systems, which describes regular, inclusive schools as the most effective means of "combating discriminatory attitudes, creating welcoming communities, building an inclusive society and achieving education for all" (Norwich in Daniels, 2000:7).

Land (1989: 122) quotes Treffinger who believes that education should focus on the development of the individual's unique abilities: "To do less, by treating all learners as if they had the same talents and needs, seems not only less 'democratic', but also unsound educationally". Colangelo believes (2005:30) that an appropriate educational response should be based on the assessment of an individual child's "gifts, curriculum needs, and motivation" to ensure that knowledge and practice connect. Grouping mixed ability learners could cause resentment and frustration, especially for gifted learners who have to work in groups with learners of lower ability. It often results in their having to assist the slower learners, do all the work and share the credit Yecke (2003:124). This "social loafing" (Yecke, 2003:126-127) and the unwillingness of gifted learners to enable other students is confirmed by Sisk (in Seevers \& Shaughnessy, 2003:18).

Many authors on gifted education believe that it is possible to teach gifted children adequately in the regular classroom (Blumen-Pardo, 2002; Bonner, 2000; Kearney, 1996; Rizza \& Gentry, 2001). Others agree in principle, but advocate separate teaching for part of the time (Freeman, 2002; Land, 1989; Sisk in Seevers \& Shaughnessy, 2003). Although Rizza \& Gentry (2001:183) believe that the use of gifted education strategies in the regular classroom will benefit all learners, the necessity of adaptations for the gifted - "one size does not fit all" (Sherman, 1997:11) -remains a recurring theme in the literature on gifted education. 


\section{Special needs of the gifted}

Delisle \& Govender (1988:75), believe the decline "in the rigor of academic options" is a negative result of inclusion practices for gifted students. They agree with Sherman (1977) and Colangelo (2005) that the focus should be on the needs of individuals and plead for gifted education to "be accepted as valid, a subcategory of special education, as legitimate as the field of mental retardation or special learning disabilities". Renzulli (in Knobel \& Shaughnessy 2002:121) says that the lack of specialised staff and learning models coupled with so-called "within-classroom differentiation" creates a "smoke screen behind which bright kids get a few extra assignments" resulting in gifted students being seriously under-served. Colangelo (2005:28-29) affirms that the gifted "aren't going to learn to the fullest extent of their abilities in the regular classroom with the regular curriculum".

Since most gifted learners in the USA work at least four grades below the desired level Gallagher advocates cluster grouping "so that 'instruction can be pitched at the appropriate level" and the gifted can interact with intellectual and age peers (in Sherman 1997:12). Sapon-Shevin however, questions the morality of ability grouping, since gifted students "might legitimately take some responsibility for enriching the lives of their non-gifted peers" (Yecke, 2003: 6). Yet, lack of attention to the needs of gifted learners results in underachievement, loss of motivation and frustration with regular classroom activities (Rosenbaum, 1989:8). In addition to catering to the needs of the gifted generally, the needs of the disadvantaged gifted require

special attention, as these could differ from the needs of other gifted learners, e.g. in regard to attitudes and interests.

\section{Elitism and equity}

The antipathy toward special schools for the gifted in Africa is described by Freeman (2002:152) as a "hangover from colonial times" when superior education was reserved for a select minority, while the majority received little education. In addition, the fundamental goal in Africa, including South Africa, is basic or primary education for all.

Borland \& Wright (1994:164) ascribe the under-representation of certain groups in gifted education programmes to the failure "as a field, to respond to our society's diversity" by adequately serving economically disadvantaged gifted students, especially those from racial and ethnic minority groups. Under-representation of learners outside the dominant culture in programmes for the gifted, and the over-representation of such learners in special education is a worldwide phenomenon (Callahan, 2005; Dorbis \& Vasilevska, 1996). 
Asmal (2003:4) ascribes the non-appreciation of "bright" learners to "misguided notions of the anti-elitist standpoint ... bright children come from all social backgrounds - the rich, the poor, urban, rural, boys and girls". Sisk (in Seevers \& Shaughnessy, 2003:29) denies that gifted programmes that challenge learners and require diligent work promote elitism: "If anything, these programmes preclude elitism".

\section{Reasons for inequity}

Reasons for the inequity between the representation of different cultural groups in programmes for the gifted, i.e. conceptions of gifted and talented, testing methods, curriculum, learning styles, home language, stereotypes of different groups and historical influences, as noted by Dorbis and Vasilevska (1996:1) will be discussed with specific reference to disadvantaged gifted learners.

\section{Conceptions of the gifted and talented}

Baldwin (2005:112-113) points out that there has been a shift in the meaning of 'gifted" from high intelligence and academic achievement to different concepts, since high intelligence and academic achievement are now widely regarded as inadequate measures. Bonner (2000:657) acknowledges the importance of culture, language and environment, while Gaydon (1988:7) suggests focusing on measuring potential, rather than manifest ability, since culturally disadvantaged learners "may not have been provided with the early learning experiences necessary to develop their potential".

\section{Testing methods (identification)}

Baldwin (2005:112-113) discusses a number of processes which can be used to identify hidden potential, especially in the culturally diverse gifted, e.g. the Baldwin Identification Matrix and Maker's DISCOVER model. Rawlinson (1999:2-3) advocates a multi-faceted approach to creating a "pool of hopefuls" across race, gender and socio-economic populations.

Concerns about including diverse learners in gifted programmes led to the promulgation of the Javits Act of 1988, which focuses on economically disadvantaged and handicapped children as well as those with limited English proficiency. The 1993 US Department of Education definition of giftedness acknowledges the outstanding talents in "children and youth from all cultural groups, across all economic strata, and in all areas of human endeavour". Porter (1999:32) cites New Zealand (Maori) and Australian (Aborigine) examples, to illustrate the increasingly multi-dimensional understanding of giftedness as it relates to 
diverse cultures: "Any definition needs to be liberal enough to recognise those talents that the child's particular culture considers valuable". Bonner (2000:654) highlights the "happy medium" between rigid nomination and selection methods and a more global approach, i.e. an approach "that does not promote under-identification of any student group".

\section{Curriculum}

The National Excellence Report (1993) of the US Department of Education indicates that gifted children in the USA often know as much as half of the curriculum content for a given grade before the school year begins. Their "opportunities for 'good learning' in the academic areas are therefore significantly less than those of their classmates, unless individual adaptations are made to the curriculum" so that gifted learners are afforded "daily opportunities to learn new things" (Kearney, 1996:5-6).

Pair, triad or small group work is recommended within an affective curriculum that provides, inter alia, for understanding the self and others, equips learners to: develop their self-concept, deal with emotional issues and cope with stress and peer pressure (Kokot, 1994:215-216; 1998:56). Toll (2000:16) recommends a variety of methods which address, among others, higher order and divergent thinking, while Bragett (in Kokot, 1998:52) promotes the view that certain strategies such as differentiation, can assist all learners in a class simultaneously, even allowing those with potential to slowly develop their talents.

Gifted learners could benefit greatly in regular classrooms with teachers who are properly trained in outcomes-based education which purports to cultivate learners who according to the Revised National Curriculum Statement (RNCS), will be able to think critically and creatively and solve problems (Department of Education, 2002:1), since the basic skills and values espoused by gifted education advocates are embodied in the Curriculum 2005 critical outcomes (Van der Horst, 2000).

\section{Learning styles}

Torrance and Reynolds (in Bonner, 2000: 649) state that individuals' varied learning styles manifest, among others, through their preferences and the efficiency they employ in applying a specific style. Since school organization is not conducive to the ways in which gifted children learn, their participation in appropriate educational opportunities is often hampered (Kearney (1996:3). Renzulli's solution to this dilemma is to analyse student interests and preferred learning styles and then to let search engines match activities (online worksheets) to the identified styles and interests (Colangelo, 2005:28). 


\section{Home language}

Natriello, McDill and Pallas (1990:26-27) found limited English proficiency to be one of the main indicators of disadvantage. The degree of proficiency in English highlights school influences as well as the importance of family and community factors, e.g. parents who do not speak English would be unable to assist their children with schoolwork. In addition, limited English proficiency could influence mathematic and other competences.

\section{Stereotypes}

Ayres \& Meyer (in Kearney, 1996:4) support the notion of "respect for intellectual diversity" and cite the use of words like "nerd, dweeb ... egghead" to taunt gifted learners and report that peers even accuse achieving, gifted, African American students of "acting white" (Kearney, 1996; Sherman, 1997). According to Bonner (2000:652) peers and even family, regard them as "sell-outs" and "pawns of white society" - thus implying that they are stereotypically unsuccessful or unintelligent. African American students sometimes attempt to realign their cultural behaviour to fit white, middle class teachers' conceptions of the gifted, thus relinquishing "cultural nuances" that identify their own racial group (Bonner, 2000). These attempts to distance themselves from negative stereotypes that teachers associate with black students often result in black self-hatred, low self esteem, heightened anxiety and low academic achievement.

Sherman (1997:3) cautions that such stereotypes "spill over into schoolrooms" and quotes the following from the National Excellence report: "We have conflicting feelings about people who are smart, and we give conflicting signals to our children about how hard they should work to be smart". He also criticises "America's ambivalence toward brains" by referring to stereotypes of scientists and professors who are portrayed as mad or absent-minded and those of doctors and attorneys who are depicted as heroes.

\section{Historical influences}

Rosenbaum (1989: 7-8) argues that exclusion from mainstream culture has resulted in restricted opportunities and inequitable funding for black learners. Furthermore impediments such as poverty and language/cultural differences have prevented them from realising their potential. Ford, Baytops, \& Harmon (1997: 201) describe concerns about the underrepresentation of racially and culturally diverse gifted students as one of the most troubling issues in education. 


\section{Teachers of the disadvantaged gifted}

In Africa, even in the $21^{\text {st }}$ century, separate education programmes for gifted children are associated with colonialism on a continent where and the primary aim is education for all. A way of breaking the elitist barrier is to include "potential" in definitions of giftedness. As Richert (1987:154) indicates, only when gifted potential is evoked in the regular classrooms with access for all students, will we be able to identify those with higher cognitive and affective potential, irrespective of their background and characteristics. The emphasis should be on individual education plans and teacher training should be woven into curriculum strategies (Toll, 2000:16). Johnsen, Haensly, Ryser \& Ford (2002:45) point out that the continuing emphasis on inclusive education and the closure of many programmes for the gifted make it essential for teachers to be trained to apply differentiation in the regular classroom in order for teachers to differentiate the curriculum "based on each child's learning style and preferred form of output" (Colangelo, 2005:31).

The individual needs of the gifted can be attended to only if teachers are well trained in understanding the affective needs of gifted learners and in addition, how particular cultures value giftedness (Blumen-Pardo, 2002; Toll, 2000). Inattention to teacher training "along with prejudice, may mean that a gifted child is overlooked because he or she is from a poor family ... or misbehaves constantly - though studies show there are as many gifted children in poor families as in rich ones" (Carpenter, 2001:4). Teacher expectations are therefore important and are especially relevant in countries like the USA where teacher nominations play an important role in the identification of the gifted (Rawlinson, 1999:2). Chhagan (1990) surmises that the notion of the "self-fulfilling prophecy" could be beneficial to learners for whom teachers have high expectations and vice versa. Frasier (1989:18) recommends emphasising high expectations for learner achievement and adapting the curriculum.

Ford et al. (1997:210) highlight the importance of staff development and teacher education in working effectively with diverse gifted learners, as teachers often focus on learners' weaknesses and could have difficulty discerning strengths in those who are economically, socially or racially different from themselves. A minimum solution would be to ensure that all pre-service and practising teachers have the opportunity for:

- early, ongoing, substantive classroom experiences with minority and gifted students;

- training to understand and respect students' cultural heritage, world views, values, customs and language;

- understanding minority students' communication skills, modalities and behaviours; understanding and decreasing misperceptions, stereotypes and fears of minority students; 
- learning outreach skills, i.e. how to work with minority students, their families and their communities;

- gaining a greater respect for individual and group differences in learning, achievement and behaviour.

Above all, all school staff, including teachers, should discard cultural deficit and pathological models in favour of accepting intelligence and educability as issues regarding individual differences, rather than racial differences (Jenkins in Ford et al. 1997:211).

\section{Research design}

The research design is a combination of qualitative and semi-quantitative methods (QUALquan).

\section{Sample}

Convenience sampling was applied to an extent, since the authors had easy access to a relatively large number of schools via the students who had been allocated to the schools for their teaching practice period. The sample consisted of 103 English and Afrikaans primary and secondary government, private and special needs (LSEN) Pretoria schools at which BEd II and III students had been placed for their three-week teaching practice period during January/February 2006. Of the 103 schools surveyed 100 responded by supplying information on provision for gifted learners.

In addition, a telephone survey of four schools was done to ascertain the types of Olympiads in which learners participate and to collect information on selection criteria for learner participation in Olympiads.

\section{Data collection and analysis}

The literature study on gifted education and the disadvantaged gifted as well as an interview and letter constitute the qualitative section of the research.

The quantitative section is comprised of responses from 100 primary and secondary government, private and LSEN schools Pretoria in regard to provision for gifted learners at those schools. 


\section{Results of the quantitative section of the study}

The graph (figure 1) indicates school responses to the various categories in regard to provision for gifted learners in Pretoria schools.

Figure 1: Provision for gifted learners in 100 Pretoria schools (percentage of respondents)

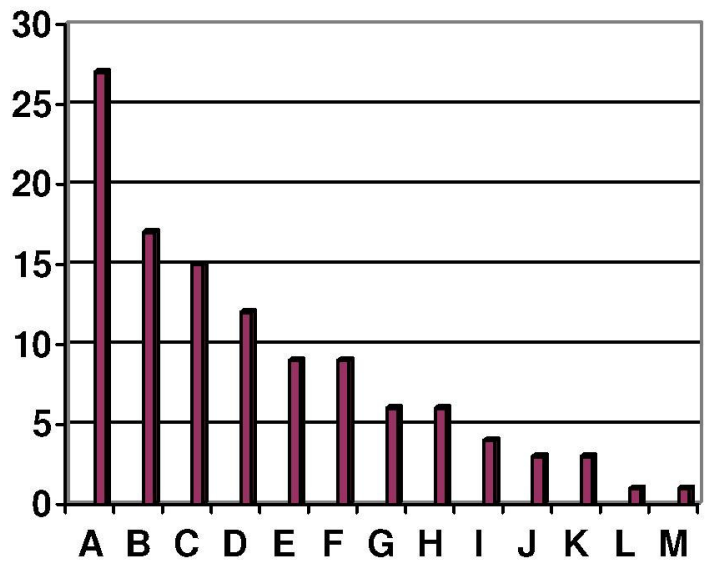

Legend:

$$
\begin{aligned}
& \text { A Extra classes } \\
& \text { after school } \\
& \text { B Excursions } \\
& \text { C Extra classes } \\
& \text { for learners } \\
& \text { with impedi- } \\
& \text { ments } \\
& \text { D No provision } \\
& \text { E Differentiated } \\
& \text { worksheets for } \\
& \text { enrichment } \\
& \text { F Therapists } \\
& \text { assist learners } \\
& \text { G Extra classes } \\
& \text { for strugglers } \\
& \text { H Participation in } \\
& \text { Olympiads } \\
& \text { I Schools apply } \\
& \text { inclusion } \\
& \text { J No gifted } \\
& \text { learners } \\
& \text { K Disabled } \\
& \text { learners } \\
& \text { L Very few } \\
& \text { gifted learners } \\
& \text { M All lessons are } \\
& \text { retaught }
\end{aligned}
$$

The results show that the majority of schools offer extra afternoon classes for gifted learners in the afternoons (A). Since six indicated that classes were offered to assist "strugglers" this could mean that they (automatically) view those with learning difficulties as gifted, or that they misinterpreted the request for information and indicated provision for learners with learning difficulties, who are not necessarily gifted (G). Fifteen respondents provide extra classes specifically for learners with learning impediments resulting from, among others, hearing/sight impairment, language difficulties, and psychological problems (C). In addition, speech therapists, audiologists and educational psychologists assist at nine schools (F). At one of the primary schools all the intermediate and senior phase lessons for the day are retaught after school every afternoon, but no additional extra classes are offered (M). Nine schools provide enrichment by means of differentiated work sheets, e.g. when learners complete regular schoolwork in less than the allotted time $(E)$. 
Three schools make special provision for disabled learners $(K)$. One has wheel chair ramps and special bathrooms, while the other two accommodate such learners in the staff room and on lower levels of the school building, arranging for teachers to teach such learners in the staff room or to move from classroom to classroom. The assumption made by the schools is that these disabled learners are gifted.

Six schools' learners regularly participate in a variety of Olympiads, e.g. English, Afrikaans, bilingualism, science, computer studies and mathematics $(H)$. A telephone survey of four schools revealed that various awards are offered, e.g. money, medals and certificates. The following selection criteria are applied to determine which learners should participate in the Olympiads: a specific percentage in relevant subjects, high overall academic achievement and teacher selection.

One of the four schools enters all its learners in various competitions with other schools where possible, depending on the competition rules. Such competitions do not offer prizes, but are used to determine the existing standards in various subjects among the participating schools. Some schools also arrange expos for specific subjects, e.g. Afrikaans and science.

Seventeen schools arrange excursions while many others do not have funding for excursions (B). The excursions sometimes include all learners in a grade or even the whole school, while at other schools only the top ten learners are taken on excursions. A primary school where no funding is available arranges "tours" of the school grounds for the learners in the special educational needs (LSEN) class and they are taught about the different types of plants, etc. in the school grounds. More traditional excursions are undertaken for educational and non-educational purposes, sometimes to reward learners for high academic achievement. Places visited include, among others, banks, the Johannesburg Planetarium, Gold Reef City (an amusement park and entertainment centre including an underground mine), and a suburban "farm" in Centurion where learners may feed the animals. One school differentiates questions based on the excursions to accommodate gifted learners who are asked "more intelligent" questions. Another school indicated that their excursions are tailored to the needs of the disabled gifted.

Twelve schools make no provision for gifted learners (D). Of these, some indicated that they encourage learners who could benefit maximally to participate in extra mural activities such as chess and drama. Four respondents specifically mentioned that they apply an 
inclusive policy and do not make special arrangements for gifted learners (I). One school makes no provision because there are "very few" gifted learners $(L)$ and three schools believe that they have no gifted learners (M).

In spite of the efforts of some schools to provide enrichment through differentiated worksheets and enrichment exercises, it is apparent that current provision for the gifted in most public and even some private schools is inadequate. This, coupled with the fact that currently almost all learners in South African schools who are gifted are also disadvantaged as a result of the lack of provision for them, as well as the fact that teachers are not trained to identify the gifted, let alone cater to their needs, is cause for great concern. The disappointing conclusion that can be drawn from this research is that all gifted learners in SA are currently disadvantaged as a result of the government's "inclusive" education policy that does not provide specifically for gifted learners, who, although found "in all grades in all communities" almost certainly remain "the most neglected children in the education system" (Alston, 2006:9).

\section{Conclusion}

A possible solution lies not only in policy change in regard to gifted education, but also in training teachers to identify gifted learners and to effectively facilitate their learning in the regular classroom, e.g. through differentiation so that they and the other, less gifted learners are enabled to work at their own pace and achieve maximally (Davison, 1996; Rizza \& Gentry, 2001; Seevers \& Shaughnessy, 2003). The view mirrored in SA government policy, namely that the "self is to be sublimated for the good of the group", needs to be adapted so that radical equity, i.e. equality of outcomes and the concomitant levelling of achievement and elimination of competition, may make way for equality of opportunity (Yecke, 2003:164).

\section{References}

Alston, K. (2006). Where have all our valuable children gone? Daily Mail, 22 February, 9.

Asmal, Kader (2003). Speech by the minister of education at the opening of the new premises of the READ Education Trust, Johannesburg, 29 July.

Baldwin, A.Y. (2005) Identification concerns and promises for gifted students of diverse Populations. Theory into Practice, Spring, 44, 2, 105-114.

Blumen-Pardo, S. (2002). Effects of a teacher-training workshop on creativity, cognition, 
and school achievement in gifted and non-gifted second-grade students in Lima, Peru. High Ability Studies, 13, 1, 47-58.

Bonner, F.A. (2000). African American giftedness: Our nation's deferred dream. Journal of Black Studies, 30, 5, 643-663.

Borland, J.H. \& Wright, L. (1994). Identifying young, potentially gifted, economically disadvantaged students. The Gifted Child Quarterly, 38, 4, 164-171.

Callahan, CM. (2005) Identifying gifted students from underrepresented populations. Theory into Practice, Spring, 44, 2, 98-104.

Carpenter, M. (2001). The IQ factor: Despite advances in defining gifted children, intelligence testing still plays a large role. Post-Gazette News. June 10.

Carrim, N. (2002). Inclusion in South African Education. Institute of Development Studies, Discussion Paper no. 2.

Chhagan, R. C. (1990). The validity of teacher nomination of gifted pupils for inclusion in a gifted programme in "Indian" schools. Research project toward the masters degree in Educational Psychology. Johannesburg: University of the Witwatersrand.

Colangelo, N. (2005). "It's time that America had a different discussion". Trend Watch, 28-31.

Davison, J. (1996). Meeting state mandates for gifted and talented: lowa teacher preparation programs. Roeper review, 19, 1, 41-43.

Delisle, J.R. \& Govender, S.P. (1988). Educators of gifted and talented students: Common bonds, unique perspectives, Roeper Review, 11,2, 73-76.

Department of Education (2001). Education White Paper 6, Special Needs Education: Building An inclusive education and training system. Pretoria: Department of Education.

Department of Education (2002). Revised National Curriculum Statement. Gazette no.: 23406. Vol. 443. May 2002 Pretoria: Government Printers. 
Dorbis, C. \& Vasilevska, S. (1996). Cultural gifts in the 90 s and beyond.

http://www.nexus.edu.au/teachstud/gat/dor vasi.htm Accessed 27 March 2006.

Ford, D.Y.; Baytops, J.L. \& Harmon, D.A. (1997). Helping gifted minority students reach their potential: Recommendations for change. Peabody Journal of Education, 72, 3\&4, 201-216.

Frasier, M.M. (1989). Poor and minority students can be gifted, too! Educational Leadership, March: 16-18.

Freeman, J. (2002). Out-of-school education provision for the gifted and talented around the world. Report to the DfES.

Gaydon, V.P. (1988). Predictors of performance of disadvantaged adolescents on the Soweto/Alexandra gifted child programme. Unpublished research report, University of the Witwatersrand.

Kearney, K. (1996). Highly gifted children in full inclusion classrooms. Highly Gifted Children, $12,4$.

Knobel, R. \& Shaughnessy, M. (2002). A reflective conversation with Joe Renzulli. Gifted Education International, 16, 2, 118-126.

Kokot, S. (1994) Understanding giftedness: A South African perspective. Durban: Butterworths.

Kokot, S. (1998). Fulfilling potential: Options for educating gifted learners in South Africa. Research report, UNISA, April 1998.

Land, D.J. (1989). A model for the provision of gifted education for black pupils in South Africa. Unpublished Med dissertation. Port Elizabeth: University of Port Elizabeth.

Naicker, S. M. (2000). Presentation: From apartheid education to inclusive education: The challenges of transformation. International education summit for a democratic society. 
Natriello, G.; McDill, E.L. \& Pallas, A.M. (1990). Schooling disadvantaged children: Racing againts catastrophe. New York: Teachers College.

Norwich, B. (2000). Inclusion in education: From concepts, values and critique to practice. In H. Daniels (ed.) Special education re-formed: Beyond rhetoric? London: Falmer.

Pandor, N. (2005). Address by the minister of education, Naledi Pandor, MP, at the EASTERN Cape Education summit, Eastern Cape Institute of Educational Leadership, East London, 13 July.

Porter, L. (1999). Gifted young children. Buckingham: Open University Press.

Rawlinson, C. (1999). Gifted and talented students: Teachers' recognition of children with special abilities. Paper presented NZARE/AARE, Melbourne, November/December, 1-3.

Richert, E.C. (1987). Rampant problems and promising practices in the identification of disadvantaged gifted. Gifted Child Quarterly, Fall, 31, 4, 149-154.

Rizza, M. \& Gentry, M. (2001). A legacy of promise: Reflections, suggestions and directions from contemporary leaders in the field of gifted education. The Teacher Educator, 36, 3, 167-84.

Rosenbaum, L.A. (1989). Enhancement of self-concept in gifted disadvantaged children. Unpublished Med dissertation. Johannesburg: University of the Witwatersrand.

Seevers, R. \& Shaughnessy, M. (2003). Reflective conversation with Dorothy Sisk. Gifted Education International, 17, 1, 16-41.

Sherman, L. (1997). Curiouser and curiouser. Northwest Education. Fall. http://www.nwrel.org/nwedu/fall/97/article2.html

Toll, M.F. (2000). The importance of teacher preparation programs to appropriately serve students who are gifted. Understanding Our Gifted, Winter: 14-16. 
Van der Horst, H. (2000). A Problem-solving strategy for gifted learners in South Africa. Gifted Education International, 15, 1, 103-110.

Yecke, C.P. (2003) The war against excellence: The rising tide of mediocrity in America's middle schools. USA: Praeger.

We express our gratitude to: Ms Elsabe Olivier, Academic Information Services: University of Pretoria, for assistance with the retrieval of information; Ms Desiree Volschenk for her assistance; the Gauteng Department of Education for permission to use information provided by schools; the 100 schools which provided the information and the January/February 2006 BEd II \& III student leaders from the University of Pretoria for obtaining information from schools. 